Sabah A Ismail

BDS, MSc (Asst. Prof.)

Moataz GH Al-shaekh Ali BDS, MSc (Asst. Prof.)

Manal A Sultan

BDS, MSc (Lec.)

\section{An Evaluation of Coronal Seal of Root Canals Prepared by Different Systems}

\author{
Department of Conservative Dentistry \\ College of Dentistry, University of Mosul \\ Department of Conservative Dentistry \\ College of Dentistry, University of Mosul \\ Department of Conservative Dentistry \\ College of Dentistry, University of Mosul
}

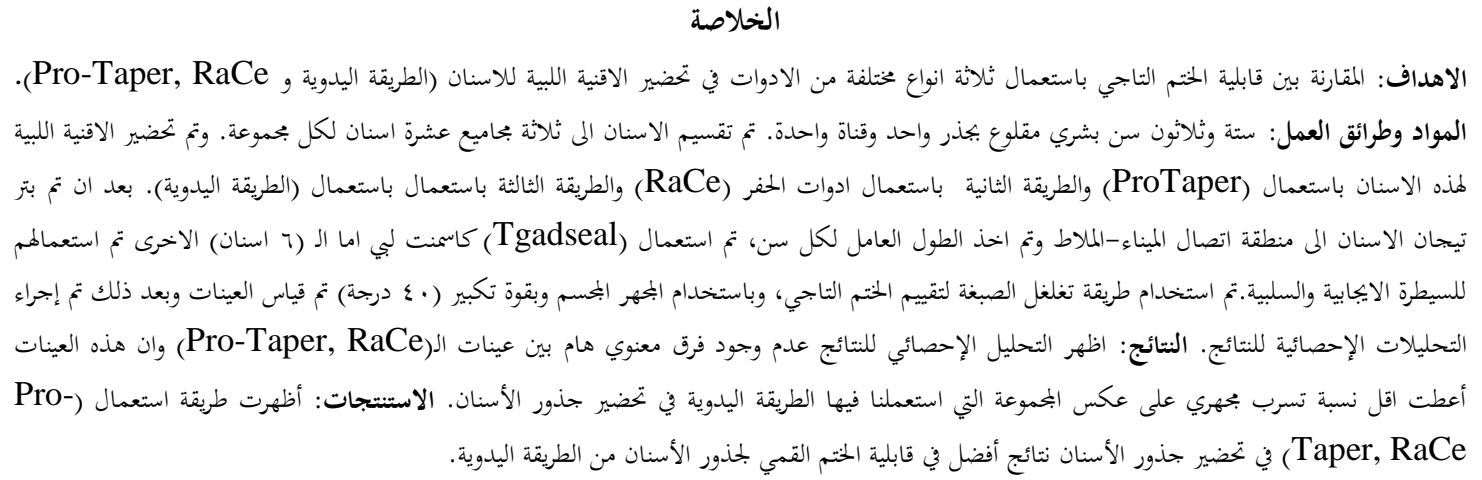

Aims: The aim of this in vitro study was to evaluate the coronal seal of root canals prepared by two NiTi systems. Materials and Methods: Thirty-six extracted human teeth with single root canal were decoronated at the cemento-enamel junction (CEJ). The working length was determined for each tooth. Thirty teeth were divided into three groups ten of each. Group I teeth were prepared by Pro-Taper NiTi rotary instruments, then obturated by matched-taper single cone. Group II teeth were prepared by RaCe NiTi rotary instruments and obturated also by matched-taper single cone. Group III teeth were prepared by hand K-files instrument then obturated by gutta percha lateral condensation technique. Remaining teeth were used as control group, three positive and three negative control. Tgadeseal was used as root canal sealer for all groups in this study. Dye penetration method was used to evaluate the coronal seal using a steromicroscope at 40X magnification. All teeth (experimental group and control groups) were longitudinally sectioned for examination of dye penetration. One-way analysis of variance and Duncan's tests was used for statistical analysis. There was significant differences between the groups $(p<0.05)$. Results: Statistical analysis of the results demonstrated that there was no statistical significant difference in coronal seal between the two systems. While, there was a significant difference between the two rotary Ni-Ti systems and the hand K-files instrument. Conclusion: The use of $\mathrm{Ni}$-Ti rotary instrument for root canal preparation shows least coronal microleakage in comparision with hand $\mathrm{K}$-files instrument.

Keywords: Coronals seal, rotary NiTi system, Pro-Taper, RaCe.

Ismail SA, Al-Shaekh Ali MGH, Sultan MA. An Evaluation of Coronal Seal of Root Canals Prepared by Different Systems. Al-Rafidain Dent J. 2013; 13(1): 95-101.

Received: $2 / 6 / 2011 \quad$ Sent to Referees: $13 / 6 / 2011$

Accepted for Publication: 10/10/2011

\section{INTRODUCTION}

The objective of root canal obturation is to seals the root canal system and prevent re-entry and/or growth of microorganisms inside the root canal system. ${ }^{(1)}$ Therefor, evaluating the quality of root canal obturation as the final stage of root canal treatment is essential. ${ }^{(2,3)}$ Different methods have been introduced for root canal obturation. An appropriate method should be able to prevent the re-entry of microorganisms into the root canals. However these methods demonstrated different degrees of sealability. This difference was due to the obturating materials and there adaptation with canal walls and their pene- 
tration into lateral canals and dentinal tubules. $^{(4,5)}$

In recent years, rotary Nickel Titanium (NiTi) instruments have become popular because of their superiority over stainless steal hand files, elasticity and resistance to torsional fracture. ${ }^{(6)}$ Moreover, rotary NiTi instruments improve working safety, shorten working time and prepare wellshaped root canals with fewer canal transportations. ${ }^{(7,8)}$

ProTaper instrument is one of the commonly used systrm that were specially designed with sharp cutting edges to provide superior flexibility, efficiency and greater safety. These instruments have a convex triangular cross-sectional design, a non cutting safety tip and an advanced flute design that combines multiple tapers within the shaft. ${ }^{(9,10)}$

RaCe which have triangular crosssectional design with alternating cutting edges and are claimed to prevent the instrument from screwing into the root canal, thus reducing intraoprative torgue values. Additionally, the surfaces of $\mathrm{RaCe}$ instruments are electrocamically treated for improvement of cutting efficacy. Some of the $\mathrm{RaCe}$ instruments for the initial steps crown down the preparation are manufactured from stainless steel as well as NiTi alloy. $(9,10)$

The aim of this in vitro study was to evaluate the coronal seal of root canal prepared by ProTaper and RaCe NiTi rotary systems, by using dye penetration method.

\section{MATERIALS AND METHOD}

In this vitro study, 36 single-rooted human extracted teeth with mature apices and single-canal configuration were used. The roots with open apices, cracks and resorptive defect were excluded. All teeth were cleaned by ultrasonic scaler and disinfected by NaOCL $0.5 \%$.

The teeth were decoronated at the (CEJ) with diamond wheel saw (KG Sorensen SP, Brazil) under water coolant. The roots were accessed, the working length was established visually by substracting $1 \mathrm{~mm}$ from the length of a K-file size \#15 (MANI, INC, JAPAN) placed at the apical foramen.

Thirty teeth were divided randomly into three groups and the remaining six teeth were divided into two groups, three negative and three positive control.

Group I : Teeth prepared with ProTaper Ni-Ti rotary instrument starting with size SX file to a size F3. A total of six instruments were used with contra-angle rotary hand piece (Endo-Mate DT, NSK, NAKANISHI, INC, JAPAN).

The speed of rotation was maintained at $250 \mathrm{rpm}$ and torque $3 \mathrm{Nm}$, EDTA gel (Bio oinamica Quim E FramLTDA, Ibipora Parana Barsil) as a lubricant during instrumentation.

Two $\mathrm{ml}$ of $2.5 \%$ sodium hypochlorite solution were used for irrigation between each file size. ProTaper files were used in the following sequence, according to the manufacturer's recommendations:

1) The pulp chamber was filled with EDTA for lubrication and the S1 file was used to enlarge the coronal twothirds of the canal.

2) The canal was irrigated using $2 \mathrm{ml}$ of $2.5 \%$ sodium hypochlorite solution using hypodermic syringe. SX file was inserted into the canal until it encountered light resistance. Shaping with SX was continued with brushing motion until two thirds of its cutting blades were below the orifice.

3) The canal was irrigated and size \#10 Kfile was used for recapitulation.

4) Shaping continued with the S1 file to the full working length.

5) Then S2 file was taken to the full working length.

6) The F1 file was taken to the full working length and immediately with drawn.

7) The F2 file was taken to the full working length and immediately with drawn.

8) The F3 file was inserted to the full working length and immediately with drawn.

During instrumentation procedure the canal irrigated with $2 \mathrm{ml}$ of $2.5 \% \mathrm{NaOCl}$ following each instrument and at the end of procedure teeth irrigated and dried. Tgadseal root canal sealer (Technical and General LTD, London-United Kindom) was used and the root canals were obturated using gutta perch for ProTaper, size F3 (Dentsply Maillfer). 
Group II: RaCe NiTi rotary instruments were used with contra angle rotary hand piece instrument. The RaCe instruments were used in crown down manner using gentle brushing motion. The instrument was withdrawn when resistance was felt and changed to the next instrument in the following sequence, according to the manufacturer's instructions:

1. The pulp chamber was filled with EDTA gel for lubrication and 0.10 taper size 40 file was used to one-third of the working length.

2. The canal irrigated using $2 \mathrm{ml}$ of $2.5 \%$ sodium hypochlorite solution and a 0.08 taper size 35 file was used to onethird to one half of the working length.

3. The canal was irrigated and a 0.06 taper size 30 file was used to one-half to two-third of the working length.

4. The canal irrigated and 0.04 taper size 25 file was used to two-third of the working length.

5. A 0.02 taper size 25 instrument was used to the full length of the canal.

6. The canal irrigated and a 0.02 taper size 30 instrument was used to the full length of the canal.

7. A 0.02 taper size 35 instrument was used to the full length of the canal.

Once the instrument had negotiated to the end of the canal and rotated freely, it was removed.

After irrigation and dryness, the canals, were obturated by the use of tgadsed root canal sealer and guttapercha for $\mathrm{RaCe}$ ( FKG DENTAIRE Swiss Dental Produce).

Group III: After access canal preparation, the pulp chamber filled with EDT gel for lubrication, the canals were prepared by early coronal flaring using GatesGlidden drills No. 4,3 and 2, followed by step-back technique using stainless steel $\mathrm{K}$-files. The canales were irrigated after each file size using $2 \mathrm{ml}$ of $2.5 \% \mathrm{NaOCl}$ solution. Recapitulation with the $15 \# \mathrm{~K}$ file carried out to the working length.

Instrumentation with hand instrument was done until size 35 file. After the preparation procedure was complete, the teeth were irrigated with $2.5 \%$ sodium hypochlorite and dried. By the use of Tagdseal root canal seal and by the cold lateral condensation technique all the teeth were ob- turated.

After obturation of all teeth, excess gutta-percha was removed at the level of canal access for all groups, the root apices were sealed with sticky wax. All teeth were incubated at $37 \mathrm{C}^{\circ}$, at $100 \%$ humidity for 7 days to allow a complete set for the sealing material. Later all teeth in experimental groups subjected to manual thermocycling for 300 cycles at $5-55 \mathrm{C}^{\circ}$ for a period of time 30 seconds. Then samples were dried for 24 hours.

In the experimental groups all roots surfaces were covered with two coats of nail polish except $2 \mathrm{~mm}$ around root canal access. The control positive left without obturation to allow maximum leakage. The root surfaces of these teeth were also coated with 2 layers of nail polish, except the $2 \mathrm{~mm}$ around canal access. The teeth in the control negative group were obturated and sealed from the coronal portion by Tetric Ceram light cured composite resin, and from the apical portion by sticky wax. The root surfaces of these teeth were completely coated by two layers of nail polish to ensure that there was no leakage.

The experimental and control groups were placed in $2 \%$ methylene blue dye for three days. The teeth were rinsed with running water and dried.

Each root was groved buccally and lingually with diamond wheel saw (KG Sorensen SP, Brazil ) under water coalant, ensuring that the root canal filling was not penetrated, and then they were split into two halves by levering with a plaster knife.

The liner extent of dye penetration from the coronal portion was measured using a stereomicroscope (Motic, TAIWAN) at (X40) magnification by two observers in millimeters.

The data were statistically analyzed using one-way analysis of variance (ANOVA) $(p<0.05)$, Duncan's tests to determine statistical significant differences between groups.

\section{RESULT}

The positive control teeth showed complete dye penetration where as the negative control teeth showed no dye leakage.

The result of one way ANOVA test 
(Table1) showed that group I and group II (ProtoTaper and $\mathrm{RaCe}$ ) represent the lowest mean of dye penetration, and the difference was statistically significant from the third group (hand instrument K-files) which showed more leakage mean. In addition to that, there was a significant difference among the three groups $(p<0.05)$, while the amount of dye penetration shown in (Figure1).

Table(1): One way ANOVA Tests for the coronal microleakage among the experimental groups

\begin{tabular}{cccccccc}
\hline Type of instrument & $\mathrm{N}$ & Range & Minimum & Maximum & Mean & Std. Deviation & Variance \\
\hline ProTaper & 10 & .30 & 2.00 & 2.30 & 2.1420 & .07714 & .006 \\
RaCe & 10 & .40 & 2.10 & 2.50 & 2.2620 & .14943 & .022 \\
HI & 10 & .60 & 3.30 & 3.90 & 3.5500 & .16499 & .027 \\
Valid N (listwise) & 10 & & & & & & \\
\hline
\end{tabular}

Sig: significant at $(p<0.05)$
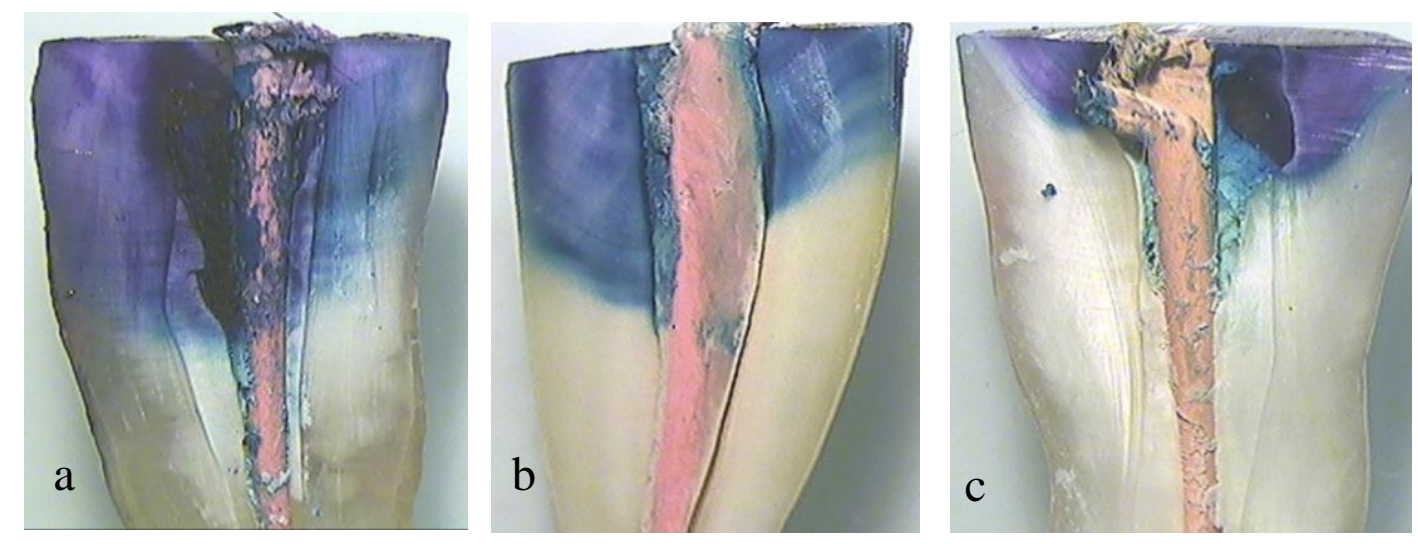

Figure (1): Evaluation of coronal seal by different preparation technique. (a) Hand instrument K-files (b) RaCe (c) ProTaper.

Duncan's multiple range test (Table 2), showed that, the difference between the two groups (ProtoTaper and $\mathrm{RaCe}$ ) was not significant $(p>0.05)$ as shown in Table(2).

Table(2): Duncan's Multiple Range Testsfor the experimental groups

\begin{tabular}{|c|c|c|c|}
\hline \multirow[b]{2}{*}{ Instrument } & \multirow[b]{2}{*}{$\mathrm{N}$} & \multicolumn{2}{|c|}{$\begin{array}{l}\text { Subset for alpha }= \\
0.05\end{array}$} \\
\hline & & 1 & 2 \\
\hline ProTaper & 10 & 2.1420 & \\
\hline $\mathrm{RaCe}$ & 10 & 2.2620 & \\
\hline HI & 10 & & 3.5500 \\
\hline Sig. & & .059 & 1.000 \\
\hline
\end{tabular}

Means for groups in homogeneous subsets are displayed. 


\section{DISCUSSION}

Obturated pulp spaces possibly be recontaminated under several clinical situations coronal leakage of microorganisms through root canal filling may be an important cause of failure in root canal therapy $^{(11)}$ Due to the loss of coronal seal, bacteria, their products and other irritants from saliva may reach the peri-radicular tissues via a lateral canal or apical foramen ${ }^{.12)}$ There are numerous factors which may affect coronal leakage these include the thickness of sealent cement, presence of voids within the root canal filling and solubility of the sealer. In addition differences in the coefficient of thermal expansion between obturating material and dentine must also be considered. ${ }^{(13)}$

The use of dye penetration method is one of the oldest and most common methods of detecting microleakage in vitro. Dyes are found to be useful as tracers because they are detectable in dilute concentrations, inexpensive, are easy to photograph, permit more reproducible results. ${ }^{(14)}$

Thermocycling is a standard protocol in restorative literature when bonded materials are evaluated simulating in vivo aging by subjecting them to cyclic exposures of hot and cold temperatures. Thermocycling stress may induce a significant amount of bond fatigue and microleakage at the tooth / restoration interface. ${ }^{(15)}$

Mechanical instrumentation is one of the important contributors to bacterial reduction in the infected root canals. The step-back techniques described by Mullaney ${ }^{(16)}$ involved preparation of the apical region of the root canal first, followed by coronal flaring to facilitate obturation when employed incurved canals. This technique often results in iatrogenic damage to the natural shape of the canal due to the inherent inflexibility of all but the smallest stainless steal files. ${ }^{(17)}$

Studies have shown that crown down techniques produce fewer canal blockages, less apically extruded debris, and a reduce incidence of apical transportation when compared to step-back technique. ${ }^{(18,19)}$ The use of NiTi rotary systems which are capable of safely preparing canals with less straightening compared with stainless steel instruments. ${ }^{(20-22)}$ Obturation was performed with resin seal (tagadseal) in all groups because of low contraction and solubility of resin sealer in comparison with ZOE-based and Calcium hydroxide root canal sealers resulting in lower leakage. ${ }^{(23,24)}$

However the results of our study showed significant differences between the sealing ability of lateral compaction and single gutta-percha cone obturation method. The finding of this study is in accordance with those of Tan B and Messer $\mathrm{H}(2002)^{(25)}$ who found that instrumentation with rotary NiTi instrument and obturation with Matched-Tapere single-cone technique produced significant coronal seal than the hand K-files instrument and cold lateral condensation technique.

The use of hand instrument and the lateral condensation technique in obturation of the root canals shown low seal as compared with the other instrumentation techniques (NiTi rotary system) and the single cone technique. ${ }^{(24)}$ Some studies have shown that lateral compaction obturation had greater microleakage due to the presence of voids and non homogenized obturation, they had the least amount of gutta-percha mass volume, and there for were unable to penetrate into canal irregularities. ${ }^{(26)}$

But the results of the present study differ from those Versumer J etal. (2002)(27) and Gutta PE etal.(2002) who promoted that there was no significant difference between rotary NiTi and hand K-files instruments in coronal seal. ${ }^{(27)}$

\section{CONCLUSION}

In the current study, both rotary NiTi systems with matched-tapered guttapercha cones showed higher coronal seal than the lateral condensation obturation technique with no different between the rotary systems.

\section{REFERENCES}

1. Gilbert SD, Witherspoon DE, Berry $\mathrm{CW}$. Coronal leakage following three obturation techniques. Int Endod $J$ 2001; 34:293-9.

2. Monticelli F, Sword J, Martin RL, Schuster GS, Weller RN, Ferrari M, Pashley DH, Tay FR. Sealing proper- 
ties of two contemporary single-cone obturation systems. Int Endod J 2007; 40:374-85.

3. Yamauchi S, Shipper G, Buttke T, Yamauchi M, Trope M. Effect of orifice plugs on periaplical inflammation in dogs. J Endod 2006;32:524-6.

4. Gopikrishna V, Parameswaern A. Coronal sealing ability of three sectional obturation techniques-SimpliFill, Thermafil and warm vertical compaction- compared with cold lateral condensation and post space preparation. Aust Endod J 2006; 32:95-100.

5. Hailertvanitkul P, Saunders WP, Saunders EM, Mackenzie D. An evaluation of microbial coronal leakage in the restored pulp chamber of root-canal treated multirooted teeth. Int Endod J 1997;30:318-22.

6. Namazikhah S, Shirani R, mohseni A, FarsioF. Dye leakage study: comparing conventional and new techniques. J Calif Dent Assoc 2000;28:435-42.

7. Sevimay S, Kalayci A. Evaluation of apical sealing ability and adaptation to dentine of two resin-based sealers. J Oral Rehabil 2005;32:105-10.

8. De Almeida WA, Leonardo MR, Tanomaru Filho M, Silva LA. Evaluation of apical sealing of three endodontic sealers. Int Endod J 2000; 33:25-7.

9. Kandaswamy D, Venkateshbabu N, Reddy GK, Hannah R, Arathi G, Roohi R. Comparison of laterally condensed, vertically compacted thermoplasticized, cold free-flow GP obturations-A volumetric analysis using spiral CT. J Conserv Dent 2009;12:145-9.

10.Ayar L, Love RM. Shaping ability of ProFile and K3 roatry Ni-Ti instruments when used in variable tip sequence in simulated curved root canals. Int Endod J 2004; 37:593-601.

11. Madison S, Swanson K, Susan A. An evaluation of coronal microleakage in endodontically treated teeth. Part II. J Endod 1987;13:109-112.

12.Claudia R, Stefan Z, Ralf W. Long term bacterial leakage along obturated roots restored with temporary and adhesive fillings. J Endod 2001; 27:559562.

13. Youssef H, William W, Geoff B.A new method for the quantitative analysis of endodontic microleakage. J Endod 1999;25:172-173.

14. Scott M. Scott B. Goodell G. The effect of thermocycling on a colored glass ionomer intracoronal barrier. J Endod 2005;31:526-528.

15.Korsali D, Ziraman F, Ozyurt P, Cerhrali B. Microleakage of self-etch primer / adhesive in endodontically treated teeth. J Dent Am Assoc 2008;138:634-640.

16. Mullaney TP. Instrumentation of finely curved canals. Dent Clin North Am 1979;23:575-592.

17. Glossen C, Haller R, Dove B, del Rio C. A compassion of root canal preparations using Ni-Ti hand, Ni-Ti enhindriven, and-Flex endodontic instruments. J Endod 1995; 21: 146-151.

18. Weine F, Kelly R, Lio P. The effect of preparation procedures on original canal shape and on apical foramen shape. J Endod 1975;1:255-262.

19. AlOmari M, Dummer P. Canal blockage and debris extrusion with eight preparation techniques. J Endod 1995; 21:154-158.

20.Fan B, Wu MK, Wesselin KPR. Leakage along worm gutta percha fillings in the apical canals of curved roots. Endod Dent traumatol 2000; 16:29-33.

21. Wsposito P, Cunningham C. A comparison of canal preparation with NickleTitanium and stainless steel instruments. J Endod 1995; 21:173-176.

22. Gluskin A, Brown D, Buchanon L. A reconstructed computerized tomographic comparison of NiTi rotary GT files versus tradional instruments in canal shaped by novice operators. Int Endod J 2001; 34:476-484.

23.Sevimay S, Kalayci A, Evaluation of apical sealing ability and adaptation to dentin of two resin-based sealers. J Oral Rehabil 2005;32:105-110.

24.Siqueira JFJr, Racars IN, Favieri A, A bad EC, Castro AJR, Gahyva SM. Bacterial leakage in coronally unsealed root canals obturated with three different techniques. Oral Surg. Oral Med. Oral Pathol. 2000; 90: 647-50.

25.Tan BT, Messer HH. The quality of apical canal preparation using hand and rotary instruments with specific criteria 
for enlargement on initial apical file size. J Endod 2002; 28(9) : 658-664.

26. Montice F, Sadek F, Schuster G, Volkmann K, Looney S, Ferrari M, Toledano M, Pashley D, Tay F. Efficincy of two contemporary singlecone filling techniques in preventing bacterial leakage. J Endod 2007; 33: 310-3.

27.Versumer J, Hulsmann M, Schafers F. A comparative study of root canal preparation using profile. 04 and lightspeed rotary instruments. Int $\mathbf{J}$ Endod 2002; 35: 37-46. 